\title{
Nos interstícios das sociedades ocidentais em mutação, a que tipo de comunidade a pluriparceria sexual contemporânea diz respeito?'
}

\section{Into the interstices of changing western societies, what kind of community contemporary sexual plural parceria concerns?}

Philippe Combessie

Professor Université Paris Ouest Nanterre La Défense, Doutor em Sociologia (Paris 8) e Membro do Conseil Scientifique du GIP (CNRS-Ministère de la Justice) e Diretor do Sophiapol (EA3932) - Laboratório de Sociologia, Filosofia e Antropologia Política. $<$ combessie@gmail.com>

\section{RESUMO}

Se o terreno das lutas políticas é hoje marcado por pessoas que reivindicam uma orientação sexual específica, e se essas pessoas chegam a obter o reconhecimento de seus direitos individuais a partir de orientações que se desenvolvem dentro do quadro de uma sexualidade circunscrita ao seio de uma relação diádica, isso se passa de outro modo no que se refere às práticas sexuais coletivas, que parecem permanecer no escuro. A propósito das sociedades Inuits, nas quais tais práticas permaneciam frequentes no início do século $\mathrm{XX}$, Mauss desenvolveu o conceito de comunismo sexual. Tal conceito é aplicável às relações que se desenrolam nos dias de hoje entre os praticantes destas formas de sexualidade heterodoxas? A análise das modalidades, segundo as quais os seus adeptos se encontram e mantêm ou não suas relações, permite ao menos compreender as questões, os limites e as margens de manobras em torno de tais práticas, bem como que se pergunte em que medida estas resultam na constituição de uma forma de comunidade.

\begin{abstract}
Political struggles today are marked by people who claim a particular sexual orientation. If they can obtain recognition for their individual rights from guidelines that are developed within the framework of a circumscribed sexuality at the center of a relationship dyadic, it goes otherwise with regard to collective sexual practices, that appear to remain on the dark. In Inuit societies where such practices were still common in the early 20th century, Mauss developed the concept of sexual communism. This concept applies to relationships that take place between the practitioners of these forms of unorthodox sexuality. The analysis of the modalities under which its members are and keeps or not their relationship, allows at least understand the issues, the limits and margins of maneuver around such practices and to ask to what extent these results the establishment of a form of community.
\end{abstract}

Keywords: Sexual Communism. Communication. Community.

\section{Introdução}

Quanto ao ato sexual, Durkheim (1911) afirma que "não há ato que ligue mais fortemente os seres humanos; há uma potência associativa e,

1 Traduzido por Manuela Blanc. 
por consequência, moralizante, incomparável"; o autor se refere, portanto, implicitamente, à situação mais corrente, erigida em norma fundamental da sociedade ocidental, aquela de uma relação estritamente diádica². Em outros espaços e/ou outras épocas, as relações sexuais se desenvolveram também de forma coletiva, como no caso das sociedades Inuits a propósito das quais Mauss (1906) cunhou o conceito de comunismo sexual. Na sociedade ocidental contemporânea (Combessie, Mayer, Angell, 2013), em quais circunstâncias e sob quais condições um comunismo sexual pode se desenvolver em torno de relações de pluriparceria sexual?

Foucault demonstrou a qual ponto as injunções em torno do ato de falar sobre o exercício sexual (aos confessores, aos médicos, aos psicanalistas) têm notavelmente por função distinguir as "boas" e as "más" práticas, e sublinha como os "dispositivos sexuais" converteram o "sangue azul dos nobres [...] em uma sexualidade sã" (Foucault, 1976, p.166). Podemos nos perguntar em que medida, na sociedade contemporânea, as formas de sexualidade coletivas - a priori afastadas das normas tradicionais a tal ponto que, se tratando de práticas sexuais, tendem a ser dotadas do caráter de doentias - podem permitir a cristalização de formas comunitárias em torno de práticas hetedoroxas. Para fazê-lo, começaremos por testar a fecundidade heurística, em tal terreno, do conceito de comunismo sexual proposto por Mauss (1906), a propósito de sociedades nas quais tais práticas foram correntes.

O tipo de comunidade considerado aqui está situado nas interseções entre o que escreveram Weber (1921) sobre a "relação erótica" como "lugar comunitário" , Tönnies (1887) e Simmel (1908), a propósito da amizade, o conjunto se desenvolvendo a partir do quadro que Elias (1970) denomina como "configurações de interdependência".

\section{Nobres combates e más práticas de legitimidade}

O conceito de comunismo sexual é acionado, em geral, em função da análise de grupos de pessoas que se declaram homossexuais. Portanto, quando Dumézil (1948) desenvolve o conceito de "heresias sexuais" em torno da homossexualidade masculina, referindo-se a práticas específicas, como aquelas relacionadas à "caça amorosa". Por outro lado, privilegiar o foco na questão da orientação sexual não contribui para mascarar a heresia das próprias práticas?

2 O uso deste termo pouco corrente tem por objetivo criar um sentimento de estranhamento, um deslocamento e, portanto, desnaturalizar a norma dominante na sociedade ocidental: o casal heterossexual. 
A história recente das comunidades homossexuais se enquadra em dois tipos de questões. A primeira refere-se às lutas pelo reconhecimento desta orientação sexual: apontamentos políticos que agregam as lutas coletivas por direitos sociais, civis, fiscais ou familiares. A segunda remete às práticas individuais que, a partir do que foi dito acima, podem ser globalmente divididas em três grupos. De uma parte estão em foco as relações entre desconhecidos, assim como o analisado nos Estados Unidos por Humphreys (1970) e recentemente na França por Proth (2002) e Gaissad (2013). De outra, "a amizade como modo de vida", evocada por Foucault (1981, p.38), ou a "franco maçonaria gay", mencionada por Eribon (2003, p.27): as solidariedades interindividuais. Finalmente, estão em questão as práticas de vida em casal comparáveis àquelas das díades tradicionais heterossexuais.

As inscrições políticas e aquela referente às práticas não são passíveis de serem superpostas: a primeira concerne às ações públicas em favor dos direitos segundo uma dada orientação, a segunda às interações privadas interindividuais. Os atores envolvidos com uma dessas questões não são necessariamente ativos na outra ${ }^{3}$, mas eles interagem. Se a reivindicação de um direito ao casamento homossexual tende a se impor, é talvez devido ao fato de que ela remete implicitamente a uma relação amorosa conjugal. Ao inverso, a pluriparceria sexual pode ser tolerada, mas parece não poder ser objeto de nenhuma reivindicação política por reconhecimento.

Nos meios bi ou heterossexuais a multiplicidade de parcerias - sejam elas estabelecidas na forma de pluriparcerias sequenciais ou de sexualidades coletivas - são tão mais dificilmente legitimáveis que compartilham com os Black rooms gays as suspeitas, nem sempre infundadas, em torno da difusão do HIV (Beltzer e outros, 2005). Da estigmatização das práticas aos riscos sanitários para os seus participantes, passamos facilmente àquele das práticas de risco sob o ponto de vista social.

A legitimação é ainda mais difícil para as mulheres (Combessie, 2008). Por um lado, elas sempre dispõem de menos margens de manobras políticas do que os homens - salvo no que se refere ao seu reconhecimento sob o estatuto de vítima -, por outro lado, pesa sobre elas, mais do que sobre eles, as injunções em torno de relações sexuais estritamente circunscritas a um arranjo diádico exclusivista. A polissemia da libertinagem não é capaz de anular o estigma

3 É factual que se a questão política é indiferentemente foco de investimento tanto por homens quanto por mulheres, frequentemente associados a tipos que denominamos hoje em dia como transgêneros, mas ao que parece os dois primeiros tipos de práticas referem-se, sobretudo, aos homens. 
que pesa sobre a mulher fácil que mantém múltiplos parceiros. Para algumas, é necessário assumi-lo:

Eu prefiro que digamos vadia! Não se deve temer as palavras: uma vadia é uma moça ${ }^{4}$ que ama o sexo, e eu adoro! Então eu digo: eu sou uma vadia, e tenho orgulho disso! Assim como eu tenho orgulho de ser negra e proveniente das Antilhas! Para alguns é uma tara, para mim é um orgulho. Dá no mesmo! (Chimène, 37 anos, casada, agente comercial).

\section{Dos iglus Inuits às noites quentes parisienses.}

As sociedades, portanto, legitimam formas de pluriparceria reguladas. Mauss (1906) descreve notavelmente o caso Inuit: Estas trocas ocorrem no inverno entre todos os homens e todas as mulheres da localidade. Durante um instante, podemos dizer, o clã, em todo o seu amorfismo, absorve a família. Além desses intercâmbios generalizados que ocorrem entre todos os membros do grupo e que assumem o caráter de ritos sexuais, existem outros, mais ou menos permanentes, que se estabelecem entre os indivíduos particularmente. Mauss sublinha a intensidade das solidariedades e da integração social que decorrem daquilo que ele denomina comunismo sexual:

O comunismo sexual é uma forma de comunhão, e talvez a mais íntima delas. Quando ele se estabelece se produz uma espécie de fusão das personalidades individuais de uns e outros [...] [Esta fusão] afeta [...] as ideias, as representações coletivas, resumindo: a mentalidade do grupo (Mauss, 1906, p.97-98).

Estas solidariedades se desenvolvem também entre pessoas de filiações diferentes, criando laços de parentesco:

Os homens que estabelecem tais intercâmbios tornam-se irmãos por adoção, as mulheres são consideradas como irmãs umas das outras, e se passa o mesmo entre todas as crianças nascidas destas uniões. [...] Estas se tratam portanto de novas provas de que os grupos nos seios dos quais se pratica o comunismo sexual se constituem grupos de parentesco mesmo quando este se estabelece entre estranhos, esta prática cria entre eles um laço de parentesco (Mauss, 1906, p.109110).

4 Traduzido do termo nana (nota do tradutor). 
Estas práticas envolvem todos os "indivíduos núbeis" de grupos nos quais a característica comunal é fundamentalmente, ligada ao conjunto da organização social, à base do clã, e isso justifica o conceito de comunismo sexual. Diferentemente dos Inuits, do início do século $X X$, as práticas que eu estudo dizem respeito apenas a uma ínfima parte da sociedade francesa5: elas são fragmentadas e de fato estigmatizadas. As sexualidades coletivas das quais participam as mulheres que aceitam me reportar seus "pequenos segredos" ${ }^{6}$ não revelam práticas comunais nos termos usados por Mauss (1906) quanto aos Inuits. Os modos comunais de se relacionar que elas engajam parecem dever ser analisados em referência a três aspectos da nossa sociedade, que interferem nas suas condições de reconhecimento, de facilitação ou de limitação: o desenvolvimento do individualismo, dos meios de comunicação e das trocas monetárias (Combessie, 2015).

\section{O individualismo e a emancipação das mulheres}

O desenvolvimento do individualismo é acompanhado de um processo que convém chamar de emancipação das mulheres, o seu acesso cada vez mais fácil a funções, status e práticas em outros tempos reservados aos homens. Em matéria de sexualidade, esta emancipação foi facilitada por um grande controle da fecundidade. Esta evolução, por outro lado, transpõe as fronteiras, mas não as suprime; sob estas reconfigurações perduram formas de se relacionar socialmente, marcadas pela dominação masculina, sobretudo no domínio doméstico. Raros são os homens que aceitam "compartilhar" suas companheiras sob cuja sexualidade parece se continuar a reivindicar uma forma de direito exclusivo. Toda relação sexual é implicitamente uma relação dual ${ }^{7}$. A invenção do casamento por amor modificou as relações conjugais, mas sem colocar em questão a norma social dominante que convida, sobretudo às mulheres, a correlacionar todo intercâmbio sexual ao estabelecimento de uma relação diádica e, se possível, perene.

5 Em 2006, 0,6\% das mulheres e 2,2\% dos homens interrogados pela enquete CSF declararam ter estabelecido relações sexuais em espaços dedicados às práticas de sexualidade coletivas [Bozon, 2008, p.278].

6 Eufemismo que remete as práticas que elas devem frequentemente manter estritamente escondidas de seus conviveres próximos, em particular em termos de vizinhança, vida familiar ou meio profissional. 7 Esta metáfora se refere a cinco elementos: um número de parceiros limitado a dois, um intercâmbio cujo desenrolar é socialmente codificado, uma dinâmica que implica relações corpo a corpo, uma questão em torno da honra dos participantes (mais do que o observável nas demais relações a dois, as relações sexuais colocam em questão elementos importantes em torno da honra dos participantes, como nos duelos da Idade Média), e uma forma de combate (o vocabulário mobilizado - o uso de termos de guerra provém do verbo "possuir" - evoca este aspecto de batalha). 
As mulheres são mais livres sexualmente nos períodos de celibato, fases estas muito mais prolongadas e frequentes nos dias de hoje que em outras épocas: o individualismo o o prolongamento da expectativa de vida são correlatos ao aumento do número de rupturas conjugais. Esses períodos, finalmente, oferecem às mulheres ainda mais possibilidades de estabelecer múltiplas parcerias dado que elas podem justificar tais práticas inscrevendo-as em uma perspectiva de busca de uma parceria durável (Combessie, 2015). Tal fenômeno propicia um caminho diferente daquele que descrevemos tradicionalmente quando planejamos um encontro baseado em centros de interesse comuns "com ainda mais afinidades"; "agora [disse-me uma informante] eu começo por testar a compatibilidade [dos meus parceiros] em termos sexuais... [antes de um eventual compromisso sentimental]".

\section{O avião, o trem, o carro... e a internet!}

O desenvolvimento dos meios de transporte facilita os deslocamentos, vide os fluxos migratórios, alargando o círculo dos encontros ${ }^{8}$. A pluriparceria sexual, tendendo particularmente a se desenvolver a partir de pessoas melhor dotadas de capitais sociais diversos, estas práticas podem ser utilizadas como via de integração social pelas pessoas originárias de meios comparáveis, porém provenientes de países do Sul ou do Leste, e que desejam uma integração rápida na sociedade ocidental (constituição de novas redes amigáveis, estratégias matrimoniais ou profissionais).

A internet favorece um incremento considerável de todas as redes de adeptos de práticas marginais, sejam quais elas forem ${ }^{9}$. 0 intercâmbio de fotos e imagens em webcam permite testar uma eventual atração física entre desconhecidos. O strip-tease diante de uma câmera de computador constitui em certos casos a primeira etapa de um processo que podemos considerar como uma iniciação, em particular para os mais jovens e futuros adeptos destas práticas.

8 Gabriel Tarde notou em 1902 (2008, p. 38-39): "Há em toda sociedade [...] dois círculos concêntricos, um deles circunscreve o conjunto de pessoas com as quais o casamento é interdito, considerado incestuoso, e o outro limita o grupo de pessoas com as quais é impossível se casar. É considerável que em todo progresso da civilização tende por efeito a contrair o mais estreito destes círculos e a expandir o mais largo".

9 Ela resulta no desenvolvimento daquilo que certos pesquisadores deniminam "comunidades virtuais" (Schrecker, 2007, p. 221-245), mas tal não é o caso dos grupos descritos aqui, para os quais a internet é um meio de desenvolvimento de uma rede comunitária em torno de encontros não virtuais. 


\section{O sexo e o dinheiro}

O desenvolvimento das trocas monetárias introduz em compensação muitos obstáculos à pluriparceria sexual de tipo comunitário: de uma parte implica no risco de assimilar certos intercâmbios sexuais à prostituição, prática de conotação negativa na sociedade ocidental contemporânea ${ }^{10}$, por outro lado, rompe com o laço criado pelo intercâmbio sexual na medida em que a remuneração de um intercurso sexual pode perturbar a dinâmica de uma troca do tipo dom e contra-dom na qual a reciprocidade é uma condição ao desenvolvimento de um laço comunitário.

Um retorno a uma análise proposta em 1977, por Béjin e Pollak, coloca em evidência a aparição de uma nova configuração das trocas desigualitárias, permitindo aprofundar esta questão dos obstáculos estabelecidos pelas difíceis relações entre o sexo e o dinheiro. Sobre o termo "revolucionismo sexual", eles descrevem uma configuração social de trocas que "florescem" nas camadas jovens de frações dominadas e ascendentes da classe dominante [...] (intelectuais, artistas, profissionais liberais, estudantes). Eles sublinham a desigualdade:

A troca sexual, mesmo quando envolve formalmente trocas entre equivalências, é de fato uma troca desigual que beneficia àqueles que dispõem de uma quantidade suficiente de bens não sexuais (estéticos, materiais, simbólicos) e que, respeitando as regras de um mercado que lhes oferece vantagens, são mais capazes de se distanciar destas regras, de jogar com elas (Béjin e Pollak, 1977, p.119).

Eles analisam a dinâmica do desenvolvimento das relações sexuais que desvalorizam os "sem valor" em proveito dos "saciados":

Enquanto os sem valor são frequentemente limitados a se descarregar periodicamente em benefício de uma prostituição que se industrializa [...], a exercitar a sua produtividade sexual em práticas sexuais fundadas sob o desejo-desprezo, os novos "saciados" da sexualidade moderna tendem a [...] melhorar sua posição na hierarquia [...] social acentuando a desvalorização sexual dos outros agentes e, portanto, o caráter desigual das trocas de satisfação com

10 E singularmente em países que, como a França, adotaram oficialmente um ponto de vista dito abolicionista sobre a prostituição. Acontece que certas pessoas que praticam o escorting (Bigot, 2008) apreciam também, em âmbito privado e gratuito, a pluriparceria, momentos nos quais têm todo interesse em mascarar as fontes de seus ganhos. A difícil legitimação da pluriparceria sexual torna os seus adeptos muito sensíveis quanto ao que pode transmitir a sua imagem, assim eles estão empenhados em excluir de seus grupos pessoas que misturam dinheiro e sexo. Remarcamos que este ostracismo não diz respeito aos profissionais do cinema pornô. 


\begin{abstract}
os mesmos. Dominando as regras de avaliações sexuais recíprocas, hábeis a converter incessantemente suas vantagens de uma esfera a outra (material, sexual, simbólica), a aprimorar seus corpos como símbolo de uma valorização eficaz (vestimenta e outros ornamentos) e em uma apresentação de si adequadamente diferenciada segundo o lugar no qual seus corpos se inserem por um período determinado, estes 'saciados' se caracterizam de outra forma pela plasticidade normativa e'tolerância' (Béjin e Pollak, 1977, p.119-120).
\end{abstract}

Nos grupos de adeptos de sexualidades coletivas, minhas pesquisas me permitiram verificar a dificuldade encontrada pelas mulheres de origens modestas para operar sobre elas mesmas o trabalho necessário para adotar uma plasticidade normativa e tal tolerância. Eu me limito aqui a evocar a dimensão a partir da qual a questão do dinheiro cristaliza estas dificuldades e limita o desenvolvimento das relações. Estas mulheres aceitam, de forma mais resistente, convites efetuados por pessoas mais ricas, homens ou mulheres, mesmo no âmbito das trocas menos visivelmente sexuadas. As manifestações de solidariedade amigável correntes (convites a restaurantes, pagamento de um táxi para o retorno a casa, etc.) são para elas tão mais difíceis de aceitar quanto mais o objeto central do encontro é de natureza sexual. Nestas situações, o dinheiro pode tornar-se um fator de tensão intracomunitário e de reativação da tensão inerente a sua referência à dominação masculina. Uma restrição ao estabelecimento de relações se segue, uma restrição progressiva destas mulheres talvez se anuncie de acordo com a base social de recrutamento de parceiros duráveis.

De forma ainda mais direta, o dinheiro impõe limites ao desenvolvimento equilibrado das relações. Os encontros de sexualidade coletiva demandam uma infraestrutura. Se ela é comercial (boates, saunas, etc.) deve ser rentável. Se ela depende de particulares, deve-se assegurar uma forma de compartilhamento de custos; não se pode reunir trinta pessoas, ${ }^{11}$ todo final de semana, sem oferecer o que é necessário para acolhê-las, restaurar-lhes o ânimo, etc. O dinheiro deve, portanto, poder circular livremente, assim como os pequenos agrados, signos de atenção que são como demonstrações de cumplicidade ao seio da coletividade (Combessie, 2015).

Segundo esse mesmo padrão, a desigualdade que limita as relações de troca de uns favorece o desenvolvimento de intercâmbios entre outros sobre a base de uma espécie de homogeneidade social pré-estabelecida, cuja natureza tende a intensificar o sentimento difuso de comunidade que ela mesma

11 Algumas destas "festas privativas" reúnem mais de uma centena de pessoas. 
promove. Esta tendência pode, desta forma, levar também à marginalização do grupo. As condenações morais das quais esses comportamentos são objeto conduzem a estratégias comuns de diversos tipos em favor da manutenção do anonimato das redes de relações ativas, assegurando aos seus membros uma grande discrição dado que a divulgação das práticas é um risco que poderia comprometer a sua reputação. O mesmo comportamento foi observado por Manuela V. Blanc (2013), em um estudo empírico, realizado nas cidades de Paris e do Rio de Janeiro ${ }^{12}$.

\section{Figuras e condições atuais de uma pluriparceria sexual comunitária}

Estas estratégias em torno da manutenção de pluriparcerias sexuais articulam dispositivos individuais específicos e um interesse comum ao desenvolvimento de redes de inter-relações e de solidariedade.

A partir da plasticidade normativa que caracteriza certos grupos mais do que outros, assim como o demonstrado anteriormente, os dispositivos individuais se encarnam através de múltiplos ajustamentos que permitem domesticar seus próprios corpos, no estabelecimento de relações com outros corpos, para torná-los aptos, aceitáveis, finalmente mais aprazíveis (Becker, 1963), desenha o mesmo caminho em torno do consumo de maconha - a uma forma mais ou menos avançada de pluriparceria sexual ${ }^{13}$.

O desenvolvimento destas redes de convívio e solidariedade incita a formação de um grupo que podemos denominar intermediário, qualificação que corresponde a duas lógicas complementares. É intermediário, dado que ele estrutura ${ }^{14}$ o elo entre as pessoas que vão participar desses encontros sexuais. $A$ rede é intermediária, por outro lado, por centralizar a elaboração de regras éticas

12 A autora identificou ainda diferenças entre libertinos sexuais em ambos os países, que se referem sobretudo à construção identitária - variante entre libertinos e swinguers em termos de práticas e valores (Blanc, 2014).

13 Comparei certos comportamentos que me foram descritos sobre a forma de "percursos", típicos à uma iniciação tribal. Estes referiam-se à trajetória de mulheres em torno de uma domesticação de seus corpos em função de práticas de pluriparceria sexual e me parece que podemos distinguir cinco fases: 1) consolidação, 2) entraves à progressão, 3) aprofundamento, 4) entraves à consolidação e 5) regularização por especialização.

14 A questão da complementaridade dos membros de uma comunidade raramente é estudada (Schrecker, 2007). Os adeptos de sexualidades coletivas não compartilham todos das mesmas expectativas. Algumas mulheres, por exemplo, apreciam mais do que outras a pluralidade masculina. Uma solução consiste em segmentar. É desta forma que em dado evento (em em dado espaço) haverá tantos homens quanto mulheres, enquanto em outro evento (ou local) as proporções serão diferentes. Parece, finalmente, que o número de mulheres nunca é mais acentuado do que o de homens, ou sequer significativamente proporcional. A orientação sexual (bi ou hetero) é outro parâmetro a ser levado em consideração para que um encontro seja considerado bem sucedido e para que os laços comunitários sejam reforçados. Sobre esse assunto, Bartell (1971) nota que a bissexualidade feminina 
específicas. Por sua existência mesma, ela participa da construção social de normas sexuais alternativas (Richie e Barker, 2006). “O ato sexual [...] movimenta [...] a consciência moral [...] em sentidos contrários", afirmara Durkheim (1911, p.42); essas emoções morais contrárias tomam a forma de injunções contraditórias que, no que se refere às mulheres da sociedade contemporânea, conduzem a uma oposição caricatural entre a figura da dama ${ }^{15}$, de um lado, personagem que faz amor quase assexuadamente, e de outro, aquela da puta. Mas os saberes práticos desenvolvidos na medida em que progridem em uma vida sexual de múltiplas parcerias permitem às mulheres acumular as vantagens destas duas figuras: obter a liberdade de seus corpos por essa desconexão entre a sexualidade e a díade exclusivista, atribuída à puta, conservando a respeitabilidade da dama ${ }^{16}$. Os grupos de sexualidade coletiva não podem se desenvolver senão a partir de redes de membros que construam conjuntamente modelos alternativos de articulação entre práticas sexuais e comprometimento afetivo - articulação central para todas as questões em torno da moral sexual.

A moral dominante na sociedade contemporânea liga fortemente 0 comprometimento afetivo à exclusividade sexual, particularmente do ponto de vista das mulheres. Sublinhamos a analogia de situação entre aquilo que podemos observar nos grupos sobre os quais trabalhamos e aquele que descreve Tönnies ([1887] 1977, p.49) sobre os laços comunitários desenvolvidos em um contexto de amizade: “Um espírito fraternal de compartilhar de um dom oferecido de bom coração permanece vivo com certa força contra o desejo natural de guardar 'a si próprio' ou de tomar a maior quantidade possível de bens daquele que é estrangeiro".

Desde a metade dos anos 1960, dois modelos de sexualidades coletivas emergiram nas sociedades ocidentais e que distinguimos na França pelas categorias swing ${ }^{17}$, por um lado (do inglês, Bartel, 1971) e poliamor, por outro ("polyamory", Anapol, 1997). A mídia remonta voluntariamente estas duas formas de referir-se às questões de pluriparceria e que são perfeitamente reivindicadas por certos adeptos e pelos sites que lhes são consagrados na internet. Uma análise precisa das práticas demonstra que esta distinção não é necessariamente pertinente (Klesse, 2006; Combessie, 2008), ainda mais quando

é mais valorizada do que a masculina, a tendência parece menos forte hoje (Deschamps, 2002), mas a bissexualidade masculina ainda parece rara nos espaços mistos de sexualidade coletiva.

15 Do original maman (ou mamãe).

16 A estigmatização daqueles, e sobretudo daquelas, que utilizam seus corpos para se satisfazerem de forma considerada como excessiva resulta sempre em um risco de descrédito maior para os adeptos cujas práticas são desveladas (Sik Ying Ho, 2006).

17 Échangisme, do original em francês (nota do tradutor). 
lidamos geralmente com grupos de apenas algumas dezenas de indivíduos, senão grupos ainda mais reduzidos, que definem regras de vida específicas e frequentemente difíceis de assimilar a um ou outro dos citados modelos de referência. Encontramos-nos, portanto, em presença de uma multiplicidade de grupos, alguns deles não, portando senão uma existência efêmera, entre os quais as circulações são possíveis, senão frequentes, mas nenhum deles se parecendo apto a promover uma ética alternativa suficientemente geral ou englobante para satisfazer as aspirações do conjunto dos adeptos destas práticas heterodoxas. Não nos resta nada mais a fazer com relação aos comportamentos sexuais ou afetivo-sexuais aqui reunidos pelas características que lhes são comuns, além de os considerarmos como desviantes na sociedade contemporânea.

\section{Nos interstícios de sociedades em mutação}

Em sua análise de diversas centenas de gangues em Chicago, no início do século XX, Thrasher (1927) demonstra a forma com que esses diferentes grupos se desenvolvem à margem de uma sociedade em mutação, e sublinha a especificidade, bem como a variedade de princípios éticos que se forjam ao seio de cada gangue. Ele indica que seu território

constitui uma zona da cidade que é, tanto social quanto
geograficamente intersticial e precisa; que a gangue pode ser
considerada como um elemento intersticial na estrutura da
sociedade, e o território das gangues como uma região intersticial no
agenciamento da cidade" (Thrasher, 1927, p.22) ${ }^{18}$.

Parece-me pertinente, por diversas razões, emprestar de Thrasher este adjetivo e o atribuir às comunidades aqui em questão.

Diferentemente das sociedades Inuits ao seio das quais o "comunismo sexual" englobava "toda a mentalidade do grupo", na sociedade ocidental contemporânea estes tipos de práticas estão circunscritos ao seio de espaços bem delimitados e, como as gangues estudadas por Thrasher, produzem regras e valores éticos específicos a cada micro grupo, muitos se desenvolvendo à margem da sociedade dominante. O conjunto destas interações constitui, por ele mesmo, um tipo de comunidade específica, intersticial. Na medida em que tais atividades devem manter-se tão discretas quanto o possível, elas se estabelecem em espaços e tempos intersticiais da vida social ordinária: à

18 Thrasher (1927, p. 22), traduzido por Schrecker (2007, p. 151-152). Apesar dos autores mais recentes mobilizarem este conceito de espaço intersticial em antropologia urbana, pode-se notá-lo também nos trabalhos de Ulf Hannerz (1983). 
noite, em locais específicos, nas brechas, na sombra (Deschamps e Gassaid, 2008). Dado que se desenvolvem entre dois períodos da vida conjugal, elas são igualmente intersticiais sobre o plano temporal ${ }^{19}$. Elas o são ainda, e antes de tudo, em matéria de regras éticas, de valores morais compartilhados, constituídos ao seio destes grupos, segundo modos de vida sexuais ou afetivosexuais alternativos ${ }^{20}$. As regras de comportamento, frequentemente implícitas - uma forma de iniciação sendo, portanto, necessária ${ }^{21}$ - e muito estritas, que se desenvolvem no seio de um grupo, são por vezes identificadas em outros grupos, o que permite aos membros de diferentes grupos se comunicarem (sobretudo pela internet), se encontrarem de vez em quando ou mesmo passarem de um grupo a outro ${ }^{22}$. E, como nas gangues, estas comunidades devem manter-se estritamente circunscritas, sem que os praticantes, e estes ainda menos, possam esperar obter uma forma de reconhecimento social para além desses interstícios espaço-temporais. Enquanto podem existir modalidades de reconhecimento para uniões, ou mesmo casamentos, entre pessoas do mesmo sexo, na sociedade ocidental, na qual a norma sexual é a díade, toda a configuração que foge às regras é considerada suspeita, estigmatizada porque considerada um sacrilégio.

\section{Conclusão}

Na sociedade ocidental, a invenção e o desenvolvimento da união por amor, que acompanharam a progressão do individualismo (Combessie, Mayer, Angell, 2013), constituem como heterodoxas todas as formas de sexualidade que não são englobadas ao seio de uma relação sentimental que deve ser, além disso, diádica e exclusivista. Também as reivindicações de comunidades sexuais são hoje essencialmente desenvolvidas a partir de demandas de reconhecimento da legitimidade da orientação sexual e sobre modelos que, como no caso das reivindicações homossexuais, se conformam ao modelo dominante que constitui

19 Thrasher indicou igualmente que a participação em gangues se desenvolve de forma preferencial em certas fases da vida (sabidamente entre o fim da adolescência e a entrada na vida adulta).

20 No Jornal Libération, de forma ainda mais cômica do que o faz São Valentim - a quem se refere explicitamente -, Le Vaillant (2010) sugere formas conjugais de suspensão temporal ao propor uma "RTC (redução do tempo em casal)" à imagem das reduções do tempo de trabalho RTT que permitiria subordinar a "monogamia ao temperamento" (sucessão de uniões exclusivas e de rupturas qualificadas de "montanhas russas do tudo ou nada") por uma "poligamia de acomodamentos", passando por uma aliança improvisada do Eros com o Ágape".

21 Nayak (2008) descreve a evolução das práticas de "casais swinguers" como um percurso iniciático que ela distingue em quatro etapas: 1) "transgressão inicial", 2) "designação como desviantes", 3) "amplificação da carreira desviante" e, 4) "produção de normas alternativas".

22 Em matéria de sexualidades coletivas, certos praticantes não vislumbram sair do grupo ao qual se encontram ligados e ao seio do qual se sentem protegidos; encontramos aqui um comportamento simular àquele descrito por Thrasher (1927) entre as gangues. 
o par heterossexual (uniões civis, direitos à adoção pelo casal, etc.). As práticas bastante frequentes entre os homossexuais masculinos, como a pluriparceria, são, portanto, suprimidas, mascaradas, às vezes, mesmo punidas. O mesmo ocorre quanto à multiplicação de parceiros no meio heterossexual, seja no que se refere à pluriparceria sequencial ou, ainda mais, às sexualidades coletivas. Desde que Millet (2001) assumiu publicamente o seu gosto por este tipo de práticas, ela e seu parceiro se tornaram objeto de reações desaprovadoras, às quais este último respondeu em uma obra intitulada Comme si notre amour était une ordure ${ }^{23}$ (Henric, 2004).

A pluriparceria sexual, que estabelece laços tão significativos entre os indivíduos e grupos do comunismo sexual, analisado por Mauss entre os Inuits, não pode, na sociedade ocidental contemporânea que erige sobre valores sagrados a relação amorosa diádica exclusivista, ser legitimada de outra forma que não no interior de comunidades intersticiais, que se desenvolvem nas margens da sociedade. Semelhantemente às gangues de Chicago, à época da Lei Seca, estas comunidades intersticiais estabelecem, em seu seio, regras éticas que não são menos constrangedoras que aquelas da sociedade ao seio das quais se desenvolvem de forma discreta, e que acomodam perfeitamente novas organizações sociais, ligadas notavelmente ao aumento dos fluxos migratórios e às novas técnicas de comunicação. Em uma época marcada por questionamentos dos parâmetros tradicionais que tendem a reforçar os questionamentos identitários no que se refere, sobretudo, à sexualidade, elas contribuem ao desenvolvimento de uma moral e de modos de vida alternativos.

\section{Referências}

ANAPOL, Deborah M. Polyamory: The New Love without Limits. San Rafael: IntiNet Resource Center, 1997.

BAJOS, Nathalie e BOZON, Michel (org.). Enquête sur la sexualité en France pratiques, genre et santé. Paris: La Découverte, 2008.

BARTELL, Gilbert D. Group Sex. A Scientists Eyewitness Report on the American Way of Swinging. New York: Widen, 1971.

BECKER, Howard S. Outsiders. Studies in the Sociology of Deviance. New York: Free Press of Glencoe, 1963.

BÉJIN, André e POLLAK, Michaël. La rationalisation de la sexualité. Cahiers

23 Como se nosso amor fosse lixo. 
Internationaux de Sociologie, v. LXII, p. 105-125, 1977.

BELTZER, Isabelle e outros. Les connaissances, attitudes, croyances et comportements face au VIH/sida en Ile-de-France, rapport de recherche. Paris: Observatoire Régional de la Santé (Ile-de-France), 2005.

BIGOT, Sylvie. L'escorting occasionnel: une alternative sentimentale et sexuelle? In: LE GALL, D. (org.). Identités et genres de vie. Chroniques d'une autre France. Paris: L'Harmattan, p. 291-306, 2008.

BLANC, Manuela V. A sociabilidade e o lazer erótico como forma social nos contextos urbanos das cidades do Rio de Janeiro e Paris, Campos dos Goytacazes, RJ. Tese de 14 CSOnline - Revista Eletrônica de Ciências Sociais. Juiz de Fora, Ano 7, Ed. 18 set.-dez., 2014. Doutorado em Sociologia Política. Universidade Estadual do Norte - Fluminense Darcy Ribeiro, 2013.

BLANC, Manuela V. Sociabilidades eróticas em contraposição: um swing à brasileira versus uma libertinagem à francesa. In: SIMÕES, S.; SILVA, H.; MORAES, A. (Org.). Prostituição e outras formas de amor. Niterói: Eduf, 2014.

BOURDIEU, Pierre. La Domination masculine. Paris: Seuil, 1998.

BOZON Michel. Pratiques et rencontres sexuelles: un répertoire qui s'élargit. In : BAJOS N. e BOZON, M. (org.). Enquête sur la sexualité en France. Pratiques, genre et santé. Paris: La Découverte, p. 273-295, 2008.

COMBESSIE, Philippe. L'argent en milieu “libertin": entre mise en scène et occultation. Terrains/Théories [En ligne], 1 | 2015. Disponivel em: < http://teth.revues. org/422>. Acesso em: 2 jun. de 2015.

COMBESSIE, Philippe; MAYER, Sibylla e ANGELL, John. A New Econony of Sexual relations? Ethnologie française, v. 43, n.3, p. 381-389, 2013. Disponivel em: < http://www.cairn-int.info/article-E ETHN 133 0381--a-new-economy-ofsexual-relations.htm> Acesso em: 2 jun. de 2015.

COMBESSIE, Philippe. Le partage de l'intimité sexuelle. Pistes pour une analyse du pluripartenariat au féminin. In: LE GALL, D. (org.). Identités et genres de vie. Chroniques d'une autre France, Paris: L'Harmattan, p. 261-299, 2008. Disponível em: <http://halshs.archives-ouvertes.fr/halshs-00364957/fr/>. Acesso em: 2 jun. de 2015.

DESCHAMPS, Catherine. Le miroir bisexuel. Une socio-anthropologie de l'invisible. Paris: Balland, 2002.

DESCHAMPS, Catherine e GAISSAD, Laurent. Pas de quartier pour le sexe? Le développement durable des rencontres sans lendemain. EchoGéo, n.5, 2008. Disponível em: <http://echogeo.revues.org/index4833.html>. Acesso em: 2 
jun. 2015.

DUMÉZIL, Georges. Loki. Paris: Flammarion, 1986.

DURKHEIM, Emile. Débat sur l'éducation sexuelle, publié dans Textes II. Religion, morale, anomie sous la direction de Victor Karady qui est l'inventeur du titre de cet échange. Paris: Minuit, p. 241-251, 1975.

ELIAS, Norbert. Qu'est-ce que la sociologie? Paris: Aube, 1993.

ERIBON, Didier. Réflexions sur la question gay. Paris: Fayard [2003], Hérésies. Essais sur la théorie de la sexualité. Paris: Fayard, 1999.

FOUCAULT, Michel. Histoire de la sexualité I. La volonté de savoir. Paris: Gallimard, 1976.

FOUCAULT, Michel. De I'amitié comme mode de vie. In: Gai Pied, n.25, p. 38-39, 1981.

GAISSAD, Laurent. Expending Ourselves at "La Démence"? Gay Party Circuit from Consumption to Consummation. Ethnologie française, v. 43-3, p. 409-416, 2013. Disponível em: <http://www.cairn-int.info/article-E ETHN 133 0409-expending-ourselves-at-la-demence.htm>. Acesso em: 2 jun. 2015.

HANNERZ, Ulf. Explorer la ville. Eléments d'anthropologie urbaine. Paris: Minuit, Le Sens commun, 1983.

HENRIC, Jacques. Comme si notre amour était une ordure. Paris: Stock, 2004.

HUMPHREYS, Laud. Tearoom Trade. Impersonal Sex in Public Places. New York: Aldine de Gruyter, 1970.

KLESSE, Christian. Polyamory and its 'Others': Contesting the Terms of Non-Monogamy. In: Sexualities, v. 9, n. 5, p. 565-583, 2006.

LE VAILLANT, Luc. Plaidoyer pour la RTT des couples. In: Libération, n. 8943, 12 fev., p. 24, 2010.

MAUSS, Marcel (collab. BEUCHAT, Henri). Essai sur les variations saisonnières des sociétés Eskimo. Étude de morphologie sociale. In: L’Année Sociologique, tomo IX, p. 39-132, 1906. Disponível em: <http://dx.doi.org/doi:10.1522/cla. mam.ess4>. Acesso em: 30 maio 2015.

MILLET, Catherine. La vie sexuelle de Catherine M. Paris: Seuil, 2001.

NAYAK, Lucie. Normes sexuelles et contrôle social. La participation en couple à des formes de sexualité collective. Mémoire de Master 2: Université Paris Ouest, 2008. 
POLLAK, Mickaël. Un sujet inclassable. In: MENDÈS-LEITE, R. (org.). Un sujet inclassable. Approches sociologiques, littéraires et juridiques des homosexualité. Lille: Cahiers Gai-Kitsch-Camp, p. 11-13, 1995.

PROTH, Bruno. Lieux de drague. Scènes et coulisses d'une sexualité masculine. Toulouse: Octarès, 2002.

RICHIE, Ani e BARKER, Meg. There aren't Words for what We Do or How We Feel so We Have to Make. Them Up': Constructing Polyamorous Languages in a Culture of Compulsory Monogamy. In: Sexualities, v. 9, n. 5, p. 584-601, 2006.

SCHILTZ, Marie-Ange. Parcours de jeunes homosexuels dans le contexte du VIH ; la conquête des modes de vie. In: Populations. 52 ano, n. 6, p. 1485-1522, 1997.

SCHRECKER, Cherry. La Communauté. Histoire critique d'un concept dans la sociologie anglo-saxonne. Paris: L'Harmattan, 2007.

SIK YING HO, Petula. The (Charmed) Circle Game: Reflections on Sexual Hierarchy through Multiple Sexual Relationships. In: Sexualities. v. 9, n. 5, p. 547-564, 2006.

SIMMEL, Georg. Soziologie. Untersuchungen über die Formen der Vergesellschaftung, Leipzig: Duncker \& Humblot, 1908.

TARDE, Gabriel. La morale sexuelle. Préface André Béjin. Paris: Payot et Rivages, 2008.

TÖNNIES, Ferdinand. Gemeinschaft und Gesellschaft. AbhandlungdesCommunismus und des Socialismus als empirischer Culturformen. Leipzig: Fues, 1887.

THRASHER, Frederic M. The Gang. A Study of 1313 Gangs in Chicago. Chicago: The Chicago University Press, 1927.

WEBER, Max. Economie et société. Paris: Plon, 1995.

WELZER-LANG, Daniel. La planète échangiste. Les sexualités collectives en France. Paris: Payot, 2005. 